\title{
Os usos da mídia em aulas de Educação Física escolar: possibilidades e dificuldades
}

\author{
Irlla Karla dos Santos Diniz* \\ Heitor de Andrade Rodrigues** \\ Suraya Cristina Darido ${ }^{* * *}$
}

\begin{abstract}
Resumo: A mídia por meio de imagens, sons e informações influencia a maneira como os alunos interpretam a realidade. Desta forma, destaca-se a necessidade da escola refletir sobre estas questões e criar estratégias didáticas para usufruir deste aparato. O objetivo da pesquisa foi analisar algumas possibilidades de uma proposta que abordou conteúdos da cultura corporal por meio de notícias publicadas pelo Jornal $A$ Folha de São Paulo nas aulas de Educação Física. Os dados indicaram a mídia como um bom recurso pedagógico para as aulas desta disciplina, uma vez que os alunos consideraram as aulas enriquecedoras para a aprendizagem.
\end{abstract}

Palavras-chave: Educação Física escolar. Mídias sociais. Materiais de ensino.

\section{INTRODUÇÃo}

Atualmente elementos da cultura corporal possuem grande destaque no contexto midiático como jornais, revistas, rádio, internet e a televisão (TV), tendo inclusive programas e jornais inteiros dedicados aos seus conteúdos. Os meios de comunicação de massa ocupam espaço estratégico na sociedade, constituindo-se em fortes mecanismos que colocam a cultura corporal sob uma ótica jamais

\footnotetext{
"Programa Interdisciplinar de Desenvolvimento Humano e Tecnologias. Universidade Estadual Paulista Júlio de Mesquita Filho. Rio Claro, SP, Brasil. E-mail: irllakarla@yahoo.com.br

"Programa de Pós-graduação em Educação Física. Escola de Educação Física. UNICAMP, Campinas, SP. Brasil. E-mail: triheitor@yahoo.com.br

"'Universidade Estadual Paulista Júlio de Mesquita Filho. Rio Claro, SP, Brasil. E-mail: surayacd@rc.unesp.br
} 


\section{ArtigosOriginais}

vista e/ou vivenciada. Como afirma Caldas (2006) nas sociedades modernas os meios de comunicação "[...] interferem diretamente na formação/deformação das pessoas, sejam elas crianças, jovens ou adultos" (CALDAS, 2006, p.118).

As mídias, nome genérico atribuído aos meios de comunicação de massa, diariamente bombardeiam com imagens, sons e informações toda população, de maneira intensiva. Essa nova era caracterizada pela velocidade e dinamização das notícias, ocupa um espaço considerável na vida dos indivíduos, interferindo no modo como compreendem a realidade, uma vez que estão expostos, e muitas vezes ausentes de olhar crítico sobre o que recebem.

Desde 1970 que o Brasil convive mais intensamente com as mídias, isto tem se tornado tão forte que já se fala em uma Cultura da Comunicação de Massa que sobrevive graças a outras culturas que assumem caráter social e escolar (MORIN, 1984).

Os veículos midiáticos possuem grande poder principalmente sobre os jovens, que dedicam parte considerável de seu tempo para suas diversas formas de manifestação. Este fator gera forte fascínio neste público, que veem representados estilos de vida, desejos, necessidades e emoções, constituindo um panorama que inevitavelmente vai parar dentro da escola.

Betti (2001, p. 125) acredita que "[...] a cultura corporal de movimento, senão no plano da prática ativa, ao menos no plano do consumo de informações e imagens, tornou-se publicamente partilhada na sociedade contemporânea". Para tanto, o trabalho com os meios de comunicação dentro das aulas de Educação Física poderia significar maior interação aluno/professor por meio do intercâmbio de informações, otimizando o aprendizado.

Nesta perspectiva, é importante compreender o cenário produzido entre a Educação Física e a mídia, enfatizando o que muda na formação de alunos que estão inseridos no mundo da notícia, do dinamismo e do virtual, questionando como esta pode ser uma ferramenta didática para as aulas, bem como sua contribuição para uma leitura mais crítica da realidade. 
A mídia interfere diretamente no modo como os alunos recebem e interpretam as informações que são obtidas no meio escolar, influenciando o aprendizado dos mesmos, como se pode evidenciar nos estudos de Belloni (2005). Assim, o desenvolvimento de pesquisas que tratem dessas questões, faz-se essencial para que o ensino possa se adaptar a esta nova realidade.

Nesse sentido, o objetivo do presente ensaio é analisar algumas possibilidades e dificuldades de uma proposta de aulas desenvolvida em uma escola pública, em um município do interior de São Paulo, que abordou conteúdos da cultura corporal por meio de notícias publicadas pelo Jornal A Folha de São Paulo nas aulas de Educação Física.

\section{Mídia, escola e Educação Física}

As tecnologias da informação e da comunicação (TIC's) ocupam um espaço consistente dentro do nicho social, constituindose em um elemento básico do cotidiano da população. As mídias ocupam um espaço importante dentro desta nova configuração, visto que se constituem em uma ferramenta importante na disseminação da informação, por meio de suas diversas formas de manifestação (impressas, audiovisuais, on-line).

Todo avanço tecnológico da humanidade promove mudanças significativas no modo como os indivíduos veem a sociedade em que estão inseridos, atingindo níveis comportamentais, sociais, valorativos, e até mesmo de existência. Esta rede de comunicações além de permitir uma conexão de longo alcance, cria diferentes alternativas de relacionamento e novas experiências que envolvem a dinâmica dos aparatos tecnológicos. Belloni (2005) entende que:

O impacto do avanço tecnológico (entendido com um processo social) sobre processos e instituições sociais (educação, comunicação, trabalho, lazer, relações familiares, cultura, imaginário, identidade, etc.) tem sido muito forte embora percebido de modos diversos e estudados a partir de diferentes abordagens (BELLONI, 2005, p.7).

Movimento, Porto Alegre, v. 18, n. 03, p. 183-202, jul/set de 2012. 
Diante da fascinação que exercem os meios de comunicação e da sua aparente transparência, muitos educadores e intelectuais repudiam e os criticam de forma radical. Por isso, apoiam qualquer curso ou palestra que denuncie os meios, que apontem seus desmandos, exageros e mecanismos de dominação (MORAN, 1994).

Em contrapartida, Betti (2001) propõe que os educadores assumam uma posição de não preconceito com relação às mídias, buscando contato direto com as mesmas, a fim de decifrá-las, entendê-las e pedagogizá-las no meio escolar.

A linguagem como uma das principais ferramentas de ação da mídia é uma variável delicada neste contexto, uma vez que, por meio da maneira como é articulada, propaga um discurso de efeito sobre os indivíduos. Segundo Santaella (1996) toda linguagem é ideológica, pois, ao transmitir a realidade, ela obrigatoriamente a refrata, existindo assim, uma transfiguração da realidade em relação ao que acontece. Deste modo, qualquer transmissão feita pelos meios independentemente do veículo, possui linguagem deliberadamente ideológica.

Dentro da sociedade moderna nos quais os meios de comunicação são como "a vedete do capitalismo" é difícil calcular as proporções que eles têm tomado dentro da conjuntura social, assim como aferir o impacto que os fatos assumem quando passam por uma leitura midiática.

A escola enquanto instituição social, também está inserida neste contexto de intenso desenvolvimento, onde as mídias são componentes que ocupam um espaço expressivo no cotidiano. Logo, para acompanhar o ritmo dos alunos ela não pode manter-se a margem destas transformações, problematizando e refletindo sobre estas questões.

Trabalhar com materiais provenientes da mídia pode gerar dificuldades iniciais, assim, seria necessária uma preparação prévia especificamente direcionada aos professores, para que estes recursos não sejam mal utilizados, desperdiçando o que pode significar um avanço no aprimoramento das técnicas de ensino. Professores 
capacitados poderão considerar dentro da escola os conhecimentos gerados a partir dos meios de comunicação, e ensinar aos alunos como lidar com esta nova linguagem, como interpretá-la, e fundamentá-la na formação do pensamento crítico.

Neste âmbito, o professor assumiria um papel de mediador do conhecimento, tendo como princípio levantar discussões a respeito dos problemas políticos, sociais, ideológicos e econômicos que estão por trás de uma manchete, enfatizando qual o propósito da linguagem midiática.

Pensando especificamente na Educação Física como componente curricular obrigatório e parte importante na formação dos jovens, ela não se isenta desta nova ordem social, e também recebe influências diretas deste novo momento.

Para Pires (2003) existem diversas linhas de pesquisa que estudam a relação entre mídia e Educação Física, traçando objetivos e estratégias para entender possíveis relações. Para ele estas interações ficam evidentes em diversos momentos, podendo ser identificadas:

[...] no modo como os meios de comunicação de massa se apropriam e veiculam temas da área, especialmente aqueles que têm como principal objeto a produção/veiculação do esporte telespetáculo (BETTI, 1998) ou a construção da imagem social de corpo (PIRES, 2003, p. 18).

Quando os conteúdos da cultura corporal, com destaque para o esporte, passaram a constituir uma forma de espetáculo para a mídia, a Educação Física viu-se provocada e a escola passou a possuir mais um papel. Neste novo contexto, os professores precisariam considerar o impacto gerado por essa intensa disseminação de informações, encontrando na escola um espaço legítimo de discussão, reflexão e aprendizagem.

A mídia enquanto um importante fenômeno cultural entre os jovens recebe forte influência no campo pedagógico, tornando-se assim, um problema para educação, e em especial para a Educação 
Física. A influência midiática torna-se evidente no âmbito da cultura corporal à medida que sugere práticas corporais, reproduzindo-as, e transformando-as em novos modelos de consumo (BETTI, 2003).

As mídias constroem imagens na forma de objetos de consumo e entretenimento, a respeito dos componentes da cultura corporal, utilizando-os como uma espécie de combustível das máquinas publicitárias das indústrias capitalistas.

Nesta perspectiva, acredita-se que a Educação Física escolar deveria problematizar a influência que os meios de comunicação exercem no cotidiano dos estudantes, considerando as implicações sobre o imaginário da cultura corporal. Logo, é possível dizer que as:

[...] formas da cultura corporal de movimento que progressivamente vão se tornando objeto das mídias-faz parte da cultura corporal de movimento contemporânea, e tal exige da educação física escolar uma nova tarefa pedagógica: contribuir para a formação do receptor crítico, inteligente e sensível frente às produções das mídias no campo da cultura corporal de movimento (BETTI, 2011, p.127).

Para Belloni (2005) a mídia por meio de veículos como a televisão, dispara imagens que atuam na construção sistemática do imaginário dos jovens, uma vez que oferece significações por meio de mitos, símbolos e representações sociais, preenchendo o universo simbólico dos jovens com imagens irreais, estereotipando valores, normas e modelos de comportamento.

Confrontando estas ideias com os estudos realizados por Betti (2001) pode-se pensar em um espaço para reflexão/ação acerca das problemáticas que envolvem as questões do corpo/mídia dentro das aulas. Esta relação pode ser estabelecida principalmente porque nestes estudos o autor afirma que apenas uma Educação Física bem articulada pedagogicamente no sentido da vivência corporal, do conhecimento e da reflexão, seria capaz de se relacionar criticamente com as mídias no âmbito da cultura corporal. 
Os pontos positivos advindos da utilização de mecanismos midiáticos em aulas de Educação Física são muitos. Betti (2001) sugere aspectos como a motivação ao debate e a reflexão, por envolver assuntos atuais que constituem o panorama social dos alunos, a presença de outras formas de linguagens, que amplia o leque de possibilidades nas aulas, assim como a abordagem de novos materiais, criando estratégias para superar a rotina escolar.

Essas questões iniciais foram levantadas com o objetivo de entender como a mídia poderia ser vista enquanto uma ferramenta importante no desenvolvimento das aulas de Educação Física, pautando-se nos elementos da cultura corporal, a fim de fundamentar o desenvolvimento do estudo.

\section{Metodologia}

A metodologia utilizada neste trabalho foi do tipo qualitativa. Dentro das concepções de Trivinõs (1987), as pesquisas de natureza qualitativa vêm em oposição ao modelo positivista que defendia a aplicação dos mesmos princípios metodológicos para os estudos das ciências humanas e para as ciências naturais. Aabordagem qualitativa carrega características próprias, nela o ambiente natural é a principal fonte de coleta de dados, assim como o contato direto entre as pessoas.

Na primeira fase do projeto realizou-se uma análise prévia de notícias/artigos que possuíam relação com elementos da cultura corporal, no jornal A Folha de São Paulo, publicadas nos meses de janeiro e fevereiro de 2011. Após a coleta e análise, foram selecionadas as notícias que serviram como base para o desenvolvimento das aulas. A partir disso, realizou-se um plano de aplicação para adequar o desenvolvimento destas aulas, objetivando a intervenção no ambiente de pesquisa selecionado.

Após a implementação das aulas, os alunos foram entrevistados, objetivando identificar as impressões que os mesmos obtiveram das aulas, bem como outros aspectos relevantes para o desenvolvimento da pesquisa. 
O estudo foi aplicado em uma turma de Educação Física do $7^{\circ}$ ano do Ensino Fundamental de uma escola pública de um município do interior de São Paulo. Ao todo foram implementadas seis aulas de Educação Física sendo que as duas iniciais foram empregadas para observação e conhecimento da realidade no qual o estudo seria aplicado.

As aulas possuíram como ponto de partida as notícias, entretanto os conteúdos foram tratados com os alunos no intuito de resignificálos, proporcionando que os mesmos usufruíssem dos elementos da cultura corporal, por meio de outras perspectivas, incluindo vivências, debates e reflexões.

Foi utilizado um diário de campo para que todas as impressões obtidas sobre os eventos ocorridos durante as aulas fossem descritas. De acordo com Thomas; Nelson; Silverman (2007) é importante a utilização de dispositivos de registro, nos quais o pesquisador descreve reações, preocupações e especulações, favorecendo a interpretação da situação total e da interação dos atores sociais.

As perguntas realizadas ao final do estudo foram aplicadas na forma de entrevista semi-estruturada (LÜDKE; ANDRÉ, 1986) a fim de extrair respostas mais completas, viabilizando a intervenção do entrevistador. Este instrumento possibilita registrar observações sobre a aparência, o comportamento e atitudes do entrevistado, daí sua vantagem sobre o questionário (CERVO E BERVIAN, 2002).

As entrevistas foram gravadas para facilitar a transcrição e garantir maior riqueza de detalhes. Os alunos foram selecionados de forma aleatória para não comprometer a credibilidade do estudo. Elas foram realizadas individualmente em uma sala de aula no próprio prédio da escola.

O roteiro da entrevista foi composto pelas seguintes questões:

1. O que você achou das aulas? Por quê?

2. Acredita ser possível trabalhar aspectos advindos da mídia dentro das aulas de Educação Física? Por quê? 
3. Encontrou dificuldade em relacionar o conteúdo de alguma aula com a notícia/artigo proveniente do jornal?

4. Você considerou importante para o seu aprendizado a forma como a mídia foi abordada no contexto da aula?

5. As notícias ficaram claras no contexto da aula? Você teve alguma dúvida e ficou envergonhada em perguntar?

6. Qual a aula em que a relação com a mídia foi melhor estabelecida?

7. Você gostaria que normalmente o professor de Educação Física trouxesse notícias relacionadas com a disciplina para discutir na aula? Por quê?

Após as entrevistas foi desenvolvida uma avaliação final, com vocabulário simples e poucas perguntas com estes mesmos alunos, a fim de detectar o que eles haviam aprendido durante o desenvolvimento do projeto, como uma maneira de complementar os dados obtidos.

É necessário salientar ainda que o nome dos alunos, do professor responsável e da escola em que o estudo foi desenvolvido foi mantido em sigilo, e que a pesquisa foi aprovada pelo Comitê de Ética em Pesquisa - CEP, através do protocolo 1561, datado de 23/03/2011.

\section{Resultados e discussão}

O levantamento das notícias/artigos no jornal A Folha de São Paulo se constituiu em um processo de difícil desenvolvimento, uma vez que a maioria das notícias estava relacionada ao esporte e mais especificamente ao futebol. Neste sentido, pode-se dizer que apesar da Educação Física mostrar-se bastante presente nesta manifestação midiática, os conteúdos em sua maioria estão ligados aos esportes, dificultando o trabalho com demais conteúdos como a dança, jogos e brincadeiras, práticas corporais alternativas (PCAs), atividades 
circenses, atividades físicas de aventura (AFA) e capoeira. Isto culminou em dificuldades na seleção das notícias para trabalhar na Educação Física escolar.

A partir deste diagnóstico, foram selecionadas quatro notícias objetivando abordar conteúdos diversos, incluindo temas como respeito, cooperação, diálogo e criatividade. Os critérios utilizados para selecionar as notícias foram bastante flexíveis, no entanto fixouse naquelas que apresentaram possibilidades mais diretas para discutir valores, e que abordassem conteúdos que se aproximassem da realidade dos alunos participantes do estudo. Cada uma das notícias foi lida em conjunto com os alunos na forma de um resumo preparado anteriormente, a fim de facilitar a interpretação dos fatos, já que o vocabulário utilizado foi mais simples.

A primeira aula foi a mais difícil, uma vez que os alunos ainda estavam confusos com a proposta, e pouco dispostos. A notícia abordada foi "Para CBF, futebol serve a "desinformação do povo", que tratava sobre o escândalo gerado em torno da denominada "máfia do apito".

Propositalmente o futebol/futsal foi o primeiro conteúdo a ser abordado, a fim de atrair o grupo para o programa, visto que, a partir da observação inicial foi possível perceber a expectativa que eles tinham sobre este esporte. $\mathrm{O}$ assunto levantou um debate interessante sobre ética, ampliando a discussão para o cotidiano dos alunos. Um fator que mereceu destaque nesta aula foi que durante o debate, um aluno reconheceu que era errado o que havia acontecido no futebol brasileiro, porém caso algum juiz trapaceasse em favor de seu time favorito, esta atitude não seria considerada desonesta.

A inversão de valores percebida ressalta a importância do professor enquanto mediador do conhecimento que os alunos possuem e trazem para dentro da escola, saberes estes, que podem ser facilmente distorcidos ou naturalizados. A atividade docente pode contribuir para a formação crítica destes jovens, possibilitando que eles façam uma leitura reflexiva da maneira como a mídia trata a cultura corporal e como isso pode atingir a sociedade como um todo. 
A segunda aula trabalhou com a notícia "População Obesa dobrou em três décadas", neste momento o grupo parecia mais disposto, contudo a resistência ainda estava presente. O grande destaque deste dia foi a discussão final, em que os alunos puderam refletir sobre a questão da obesidade.

Nesta perspectiva ficou evidente a importância da articulação das três dimensões dos conteúdos, e a valorização por parte dos alunos de cada um destes momentos, o que ficou perceptível na roda final de conversa. Além disso, o tema de destaque foi o respeito, que a partir da construção do conceito de obesidade com o grupo, possibilitou a reflexão sobre o comportamento preconceituoso, que eles confessaram apresentar em alguns momentos.

$\mathrm{Na}$ terceira aula a notícia abordada foi: "Imagens científicas criam um mercado da esperança", na qual foram discutidos distúrbios alimentares e padrões de beleza, se caracterizando no momento do programa que obteve a maior participação dos alunos. É importante destacar que temas como anorexia e bulimia estão sendo tratados constantemente pela mídia, principalmente pela televisão que nos últimos anos tem apresentado vários casos envolvendo estes problemas. Logo, os alunos possuíam diversas informações, relatos e opiniões sobre o assunto, o que enriqueceu os debates e tornou a atividade mais significativa para àquela realidade.

A última aula teve por objetivo unir a notícia intitulada "Homens Brancos já sabem enterrar", com um seriado bastante conhecido pelos alunos, "Todo mundo odeia o Chris", o que se configurou em uma experiência bastante estimulante para o grupo. Nesta aula a dimensão atitudinal se fez muito mais presente, e a problematização em torno do preconceito pareceu natural, fator que contribuiu para que muitos alunos participassem das discussões, assim como das relações que foram estabelecidas entre a mídia impressa e a digital. No final esta proposta já parecia muito mais aceita pelo grupo, e a resistência era significativamente menor.

Uma das principais dificuldades encontradas durante a aplicação deste estudo foi a presença da dimensão conceitual nas aulas de 
Educação Física, uma vez que, o grupo não estava habituado a desenvolver estes conhecimentos nas aulas deste componente curricular.

Zabala (1998) destaca que ao longo da história da Educação determinados conteúdos, principalmente aqueles relacionados diretamente a fatos e conceitos, estiveram muito mais presentes nas propostas curriculares. Contudo, pode-se perceber que nesta perspectiva a Educação Física vem na contramão da história das disciplinas consideradas mais tradicionais (Língua Portuguesa, Matemática, etc.) já que esteve mais ligada aos conteúdos procedimentais.

Esta relação tão peculiar com a prática pode ser um dos motivos que afastou esta disciplina do trabalho em sala de aula com atividades de leituras, debates e discussões. Desta forma é natural que os alunos apresentem resistência a propostas que envolvam a dimensão conceitual.

No entanto, o que se pode destacar a partir da observação do grupo, é que no momento de leitura das notícias onde os conceitos foram inicialmente abordados, se caracterizou como o período da aula em que eles mostraram-se mais desmotivados. Os alunos não compreendiam a importância dos conceitos que estavam sendo construídos no desenvolvimento do estudo, e não conseguiam muitas vezes entender o contexto que eles poderiam ser inseridos na aula.

Ficou evidente que esta falta das dimensões conceitual e atitudinal dos conteúdos é resultado de uma construção social que foi desenvolvida gradativamente em torno do significado da Educação Física na escola. Apesar disso, é importante que não se excluam estes conhecimentos que são extremamente importantes para o processo de ensino-aprendizagem na escola, e que paulatinamente estas limitações sejam superadas. 


\section{A MÍDIA ENQUANTO UM RECURSO DIDÁTICO-PEDAGÓGICO}

Estudos envolvendo as mídias na escola estiveram durante muito tempo restrito a um uso instrumental, ou seja, enquanto "recursos" para os professores, não se pensando em maneiras para articular o processo de ensino-aprendizagem com as mídias. No entanto, já é possível identificar estudos que trazem a mídia em uma perspectiva crítica, enquanto uma proposta de trabalho para a escola, bem como para a Educação Física, como se pode identificar em (OLIVEIRA, 2004; LISBOA, 2007; BETTI et al., 2009).

Com o início do estudo os alunos se mostraram resistentes, porém sempre que as atividades eram iniciadas eles se envolviam bastante, tanto nos debates e discussões, quanto nas demais propostas realizadas durante a pesquisa.

Tendo como ponto de partida os resultados obtidos com as entrevistas e com as observações pode-se dizer que a mídia é um bom recurso didático-pedagógico para se tratar nas aulas de Educação Física. Betti (2001) coloca que esta disciplina deve aproveitar o papel que ocupa na escola para contrastar os conhecimentos advindos da cultura corporal com as experiências do "[...] assistir, ler e ouvir enquanto consumidor das mídias" (BETTI, 2001, p.128). E neste sentido construir de maneira crítica saberes que sejam mais significativos para os alunos, uma vez que terão condições de analisar o contexto com o qual mantêm contato: o universo da informação.

Trabalhar com novos materiais nesta disciplina mostrou-se como uma alternativa válida para apresentar aos alunos uma possibilidade diferente para desenvolver os conteúdos da cultura corporal. Tratar estes elementos sob uma perspectiva desafiadora levantou mais um recurso didático que pode auxiliar o professor no seu dia-a-dia, além de incentivar os alunos a buscar outras fontes de conhecimento sobre este componente curricular: "Eu achei uma coisa muito interessante por que... é a gente tava trabalhando com notícia de jornal né? Uma coisa bem diferente pra Educação Física, pro lado da Educação Física". (Aluno 1) 
Foi importante para o grupo apesar da resistência inicial, olhar para a Educação Física sob outro espectro, enxergando elementos que iam além da prática, um conteúdo contextualizado, discutido, vivenciado, e consequentemente mais significativo para o aprendizado: "Porque não seria uma coisa repetitiva, e sim mais relacionada com o assunto. Seria melhor para o aprendizado, porque não seria sempre descer e jogar futebol, ou fazer alguma outra coisa.". (Aluno 2)

As maiores dificuldades encontradas pelos alunos estiveram relacionadas com a quebra da rotina de suas aulas. Para eles era extremamente difícil entender que não iriam jogar futsal e/ou voleibol, e, além disso, realizar as leituras e discussões envolvendo os conteúdos da aula. Contudo, isso foi mudando no decorrer do estudo, e ao final eles já se mostravam mais interessados e envolvidos com a proposta, ainda que o número de aulas tenha sido bastante reduzido.

As entrevistas apontaram a mídia como um recurso importante, para ser trabalhado nas aulas de Educação Física, destacando fatores como a forte presença da cultura corporal em seus aparelhos, e o conhecimento que os alunos traziam para a aula: "É... deu pra gente conhecer um pouco mais das coisas, porque tipo, do basquete eu não entendia nada, e eu soube um pouco mais da história... tudo". (Aluno 3). É que muita coisa interessante a gente não vê dentro da escola, que a mídia traz pra gente também". (Aluno 1)

Segundo Fantin (2006), as propostas de trabalho com os meios de comunicação significam uma possibilidade de diálogo crítico e criativo com a cultura da mídia, enxergando-a como uma forma de expressão e produção cultural, ou seja, como um objeto que necessita de análise e reflexão sobre seus produtos, mensagens e discursos.

É importante que a escola acompanhe as modificações culturais e comunicacionais pelas quais a sociedade tem passado, elaborando possibilidades diversificadas de aprendizagem. Neste sentido, seria necessário que todas as disciplinas trabalhassem juntas considerando esta perspectiva, corroborando com a tese de Bourdieu (1983a), que defende a construção de um habitus que designe um estado interior geral dos indivíduos, orientando suas ações para fora deste 
espaço, ou seja, que os conhecimentos sejam transportados para sua vida em sociedade. Para este autor o habitus é compreendido como:

[...] um sistema de disposições duráveis e transponíveis que, integrando todas as experiências passadas, funciona a cada momento como uma matriz de percepções, de apreciações e de ações - e torna possível a realização de tarefas infinitamente diferenciadas, graças às transferências analógicas de esquemas [...] (BOURDIEU, 1983b, p. 65).

Partindo deste princípio, a escola teria a função de estimular a internalização do sistema de esquemas inconscientes constituintes de sua cultura, ou melhor, de seu habitus (BOURDIEU, 1974, p. 346), de maneira que fosse criada uma espécie de rotina em que o aluno não considerasse este tipo de conhecimento desconectado do conteúdo escolar. Desta forma, os alunos possuiriam maior autonomia para pensar de modo crítico a sociedade em que vivem.

Essa seria uma das razões para que a escola absorvesse a ideia de um trabalho que contemplasse uma nova perspectiva envolvendo a mídia, evitando abismos entre as experiências midiáticas e culturais dos alunos e de seus professores. O desafio está em como implantar estas ferramentas na escola como um todo, empregando esta atmosfera de informação e de conhecimentos múltiplos (MARTÍN-BARBERO, 2000).

\section{Considerações FINAIS}

As mídias ocupam um papel tão revolucionário na sociedade que transformaram a maneira como as pessoas enxergam e atuam no meio em que vivem. Este impacto tem causado interferências inclusive na concepção que os indivíduos possuem de realidade, bem como nos relacionamentos interpessoais e valores.

Neste sentido, seria importante que a escola tratasse a mídia de forma crítica, para que os futuros cidadãos não saíssem desta instituição sem a capacidade de realizar uma leitura reflexiva sobre 
esta ferramenta, filtrando as informações que são pulverizadas a cada minuto, escapando assim, de um consumo passivo e alienado.

No desenvolvimento desta pesquisa procurou-se analisar as possibilidades e dificuldades de um projeto que procurou articular algumas ferramentas da mídia, especificamente notícias do jornal A Folha de São Paulo, enquanto recursos pedagógicos para as aulas de Educação Física. Um dos objetivos foi tratar de maneira crítica a forma como a cultura corporal aparece nestes recursos e problematizá-las nas aulas desta disciplina.

Isto foi estimulado uma vez que, as aulas abriram espaço para os conhecimentos que os alunos traziam de fora da escola, tornando os conteúdos mais significativos. Neste sentido, a pesquisa qualitativa foi fundamental para explorar o ambiente de ensino-aprendizagem e construir reflexões sobre as possibilidades de articulação entre os conteúdos da cultura corporal tratados nas três dimensões dos conteúdos, bem como, a postura dos alunos diante da proposta.

Uma das principais dificuldades esteve relacionada à resistência no desenvolvimento das leituras em sala de aula, momento em que principalmente a dimensão conceitual era abordada. Os alunos não atribuíam grande importância aos conceitos, e mostravam excessivamente ansiosos para desenvolver as atividades na quadra. Além disso, existiram os problemas com os alunos que insistiam em solicitar aulas de futsal, uma vez que isto fazia parte da cultura anterior daquela escola.

Tratando-se especificamente da mídia enquanto um recurso didático pedagógico para as aulas de Educação Física, pode-se dizer a partir das entrevistas, que os alunos consideraram as aulas enriquecedoras para o seu aprendizado, destacando aspectos como a inovação e a proximidade que eles possuíam com as informações trabalhadas. No entanto, apesar deles destacarem diversos pontos positivos do programa, a resistência a novas propostas mostrou-se latente. 
Nesse sentido, este estudo foi significativo para destacar como a mídia pode se apresentar como mais uma ferramenta didática para auxiliar o professor em sua prática pedagógica, refletindo sobre o quanto elas estão presentes no cotidiano dos alunos e o quanto pode ser importante para o processo de ensino-aprendizagem.

Os resultados apontam que a utilização da mídia escrita em aulas de Educação Física, apesar de enfrentarem dificuldades de implementação, principalmente a resistência dos alunos, podem significar avanços para a área, construindo novas perspectivas para a Educação Física escolar. Sendo assim, sugere-se que novos estudos sejam desenvolvidos para que a mídia possa ser melhor problematizada no ambiente escolar, favorecendo a construção de diversas estratégias que possam contribuir com o trabalho do professor. 


\begin{abstract}
The uses of the media in school Physical Education classes: possibilities and difficulties Abstract : The media through images, sounds and information influences the way students interpret reality. This way, there is the need for the school to reflect on these issues and create teaching strategies to take advantage of this apparatus. The objective of this research was to analyze some possibilities of a proposal that addressed the content body culture through reports published by the newspaper Folha de São Paulo in Physical Education classes. The data indicated the media as a good teaching resource for classes of this course, since the students considered enriching classes for learning.

Key-words: School Physical Education. Social Media. Teaching materials.
\end{abstract}

Los usos de los medios de comunicación en
las clases de la escuela de Educación Física:
posibilidades y dificultades
Resumen: Los medios de comunicación a través de
imágenes, sonidos e información influyen en la manera
de interpretar la realidad de los estudiantes. Por lo
tanto, existe la necesidad de la escuela para
reflexionar sobre estas cuestiones y crear estrategias
de enseñanza para tomar ventaja de este aparato. El
objetivo de esta investigación fue analizar algunas
posibilidades para una propuesta que se dirigió a la
cultura del cuerpo contenido a través de los informes
publicados por el diario Folha de São Paulo en las
clases de Educación Física. Los datos indicaron los
medios de comunicación como un recurso de una
buena enseñanza para las clases de este curso, ya
que los estudiantes consideraron las clases
enriquecedoras para el aprendizaje. Palabras-clave: Educación Física. Medios de Comunicación Sociales. Materiales de enseñanza. 


\section{REFERÊNCIAS}

BELLONI, M. L. O que é mídia-educação. 2. ed. Campinas: Autores associados, 2005.

BETTI, M. Imagem e ação: a televisão e a Educação Física escolar. In: BETTI, M. (org.). Educação Física e Mídia: novos olhares outras práticas. São Paulo: Hucitec, 2003, p. 91-137.

BETTI, M.; MENDES, D.; PIRES, G. Educação física escolar: ensino e pesquisa ação. ljuí: Editora Unijuí, 2009.

BETTI, M. Mídias: aliadas ou inimigas da educação física escolar. Motriz, São Paulo, v.7, n.2, p.125-129, jul./dez. 2001.

BOURDIEU. P. A economia das trocas simbólicas. São Paulo: Perspectiva, 1974.

BOURDIEU. P. Questões de sociologia. Rio de Janeiro: Marco Zero, 1983a.

BOURDIEU. P . Sociologia. In: ORTIZ, R.(Org.) São Paulo: Ática, 1983b. p. 128155.

BRITO, D. Homens brancos já sabem enterrar. Folha de São de Paulo, São Paulo 19 fev. 2011. Caderno de Esporte. p. D8.

CALDAS, G. Mídia, escola e leitura crítica do mundo. Educação e Sociedade, Campinas, v. 27, n. 94, p. 117-130, 2006.

CERVO, A. L.; BERVIAN, P. A. Metodologia Científica. 5. ed. São Paulo: Pearson Prentice Hall, 2002.

FANTIN, M. Mídia-Educação: Conceitos, experiências, diálogo Brasil-Itália. Florianópolis: Cidade Futura, 2006.

HELVÉCIA, H. Imagens científicas criam um mercado da esperança. Folha de São Paulo, 7 mar. 2011. Caderno de Saúde. Entrevista a Rafaela Zorzanelli. p. C10.

LISBOA, M. M. Representações do esporte-da-mídia na cultura lúdica de crianças. 2007. Dissertação (Mestrado). Programa de Pós-Graduação em Educação Física - Centro de Desportos, Universidade Federal de Santa Catarina, 2007.

LÜDKE, M.; ANDRÉ, E. D. A. Pesquisa em educação: abordagens qualitativas. São Paulo: EPU, 1986, 99 p.

MARTÍN-BARBERO, J. Dos meios às mediações: comunicação, cultura e hegemonia. 2. ed. Tradução Ronald Polito; Sérgio Alcides. Rio de Janeiro: UFRJ, 2001. 
MISMETTI, D. População obesa dobrou em três décadas. Folha de São Paulo, São Paulo, 4 fev. 2011. Caderno de Saúde. p. C12.

MORAN, J. M. Influência dos meios de comunicação no conhecimento. Ciência da Informação, Brasília-DF, v.23, p.233-238, mai./ago. 1994.

MORIN, E. A integração cultural. In: Cultura de massas no século XX: 0 espírito do tempo - Neurose. Rio de Janeiro: Forense, 1984.

PIRES, G. L. A pesquisa em educação física e mídia nas ciências do esporte: um possível estado atual da arte. Movimento, Porto Alegre, v. 9, n. 1, p. 09-22, jan./ abr. 2003.

OLIVEIRA, M. R. R. O primeiro olhar: experiências com imagens na educação física escolar. Dissertação (Mestrado em Programa de Pós-Graduação em Educação Física) - Centro de Desportos. Universidade Federal de Santa Catarina, 2004.

PARA CBF, futebol serve "desinformação do povo". Folha de São Paulo, São Paulo, 01 mar. 2011. Caderno de Esporte. p. D5.

SANTAELLA, L. Produção de linguagem e ideologia. São Paulo: Cortez, 1996.

THOMAS, J. R.; NELSON, J. K.; SILVERMAN, S. J. Métodos de pesquisa em atividade física. 5. ed. Porto Alegre: Artmed, 2007.

TRIVIÑOS, A. S. Introdução à pesquisa em Ciências Sociais. São Paulo: Atlas, 1987.

ZABALA, A. A prática educativa: Como ensinar. Porto Alegre: Artmed, 1998.

Endereço para correspondência:

Irlla Karla dos Santos Diniz

Avenida 2A, 364- Cidade Nova

Rio Claro- São Paulo

CEP: $13506-780$

Recebido em: 25.04.2012

Aprovado em: 27.07.2012

Movimento, Porto Alegre, v. 18, n. 03, p. 183-202, jul/set de 2012. 
